\title{
Knowledge and Perception Level on Building Equipment Required of CMrs at the Project Design Stage
}

\author{
Jang, Young-Jun ${ }^{1}$ Kim, Jin-Dong ${ }^{1}$ Kim, Gwang-Hee ${ }^{2 *}$ \\ Dept. of Architectural Engineering, Graduate School of Kyonggi University, Suwon, 443-760, Korea ${ }^{1}$ \\ Dept. of Plant \& Architectural Engineering, Kyonggi University, Suwon, 443-760, Korea ${ }^{2}$
}

\begin{abstract}
With the rise in the functions required in modern building structures, the role of the building equipment that maintains the functions of a building has been emphasized and increased. Effective management in this area is only possible when the construction manager (CMr) is qualified and has the knowledge of building equipment that is needed. Therefore, in this study, a questionnaire survey was carried out on equipment engineers and CMrs, in order to determine the level of building equipment knowledge required, and to identify the perception level of CMrs about the building equipment in the construction project at the project design stage. The results of this study revealed that the CMrs surveyed had a lower level of knowledge on the building equipment than the level that was desired by the equipment engineers. This indicates that CMrs currently have a weak capacity for the management of building equipment. It is thus necessary for CMrs to undergo systematic training in order learn more about building equipment and thus be able to manage construction projects more efficiently.
\end{abstract}

Keywords : Building equipment, CMr's required knowledge level, CMr's perception level

\section{Introduction}

As construction managers seek greater user convenience and quality of life, the demand for building equipment has been on the rise [1]. As a result, the cost and space required for building equipment in a building construction project have also been increasing. The recent high interest in building remodeling along with the construction of large, high-rise, composite buildings and the introduction of information equipment for intelligent buildings has intensified the importance of building equipment [2].

Received : September 26, 2012

Revision received :

Accepted : October 29, 2012

* Corresponding author: Kim, Gwang-Hee

[Tel: 82-31-249-9757, E-mail: ghkim@Kyonggi.ac.kr]

(c)2012 The Korea Institute of Building Construction, All rights reserved.
In terms of construction management (CM), not only more knowledge but also the systematic management of building equipment is now required at the phases of planning, design, construction and maintenance. In particular, the functions of building equipment are not limited to a specific building itself, but need to meet the demands of all users of a building. Therefore, construction project managers (CMrs) should be equipped with sufficient knowledge of all the building equipment required to manage the equipment in an appropriate manner from the planning and design phases of a construction project. As part of building, the building equipment should be fused and reflected in a construction project [3].

This study aims to determine the knowledge level and system of building equipment required of CMrs by researching and analyzing the currently required building equipment-related knowledge 
levels and systems. The study is expected to contribute to building a system for smooth cooperation between work types and the systematic career development of CMrs in the future.

A construction project can be broadly divided by phase into planning phase, design phase, purchase and procurement phase, construction phase, and maintenance phase [4]. To understand the knowledge level and system of the building equipment that is required of CMrs, this study was conducted, but was only limited to the design phase of a construction project.

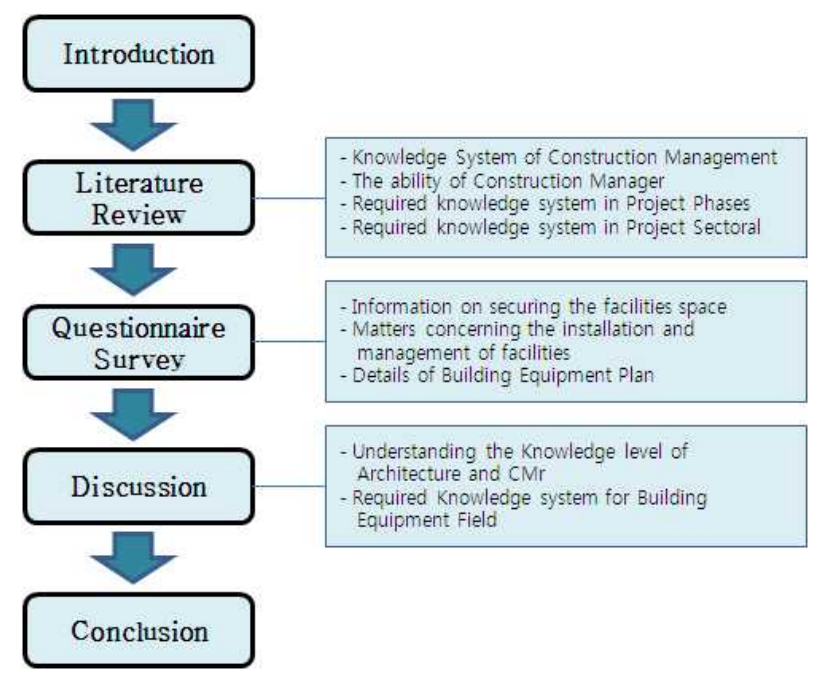

Figure 1. Research procedure

To proceed with this research, a literature review was carried out to specify the work areas of the CMrs, and identify the contribution of building equipment to the development of the construction industry and the damages arising from building equipment in the course of building construction cases, based on which the need for certain knowledge on building equipment was also analyzed. A survey was conducted of the CMrs involved in the equipment design and equipment field and the CMrs involved in the building design and construction field to analyze the knowledge expected by each group and the differences between the groups in terms of the knowledge required. Figure 1 indicates the process of this research, in detail.

\section{Literature Review}

\subsection{Review of previous studies}

As the requirements for the building structures by users have become more complex, more knowledgeable and systematic management of building equipment is required. In addition, energy-saving equipment technologies must be applied in order to reduce the environmental burden. Therefore, Table 1 indicates requirements for building equipment-related knowledge found through problems and defect type of building equipment used in the course of construction to meet the users' needs and wants.

Table 1. Previous studies on building equipment

\begin{tabular}{|c|c|}
\hline Author & Research contents \\
\hline $\begin{array}{c}\text { Ryou et } \\
\text { al. } \\
{[5]}\end{array}$ & $\begin{array}{c}\text { Investigation of CM services and practices in } \\
\text { actual projects, and suggestions to improve } \\
\text { CM services and practices are classified two } \\
\text { groups. }\end{array}$ \\
\hline $\begin{array}{c}\text { Yu and } \\
\text { Choi } \\
{[4]}\end{array}$ & $\begin{array}{c}\text { Development of a baseline from which } \\
\text { effective resource allocation of CM-oriented } \\
\text { organization and roadmap for improving the } \\
\text { CM capacity can be formulated. }\end{array}$ \\
\hline $\begin{array}{l}\text { Lee and } \\
\text { Kim } \\
{[6]}\end{array}$ & $\begin{array}{l}\text { Investigation and analysis of the characteristics } \\
\text { of owner needs and opportunities related to } \\
\mathrm{CM} \text { services in pre-construction stages } \\
\text { focused, on re-construction. }\end{array}$ \\
\hline $\begin{array}{c}\text { Yoon and } \\
\text { Chung } \\
{[7]}\end{array}$ & $\begin{array}{c}\text { Comparison of differences between CM } \\
\text { techniques in the beginning stages of } \\
\text { construction projects in Korea, Europe, and } \\
\text { Asia. }\end{array}$ \\
\hline $\begin{array}{c}\text { Kim and } \\
\text { Yoon } \\
{[8]}\end{array}$ & $\begin{array}{l}\text { Differences between past and present CM, } \\
\text { identification of recent problems and } \\
\text { suggestions of future developed items for } \\
\text { continuing development in CM area. }\end{array}$ \\
\hline
\end{tabular}

In addition to the studies shown in Table 1 , Park and Kim [3] presented the problems with the 
legal content and improvements by researching the laws and regulations that would be drawbacks to the balanced development of the construction industry or that are not appropriate for application to building equipment of construction-related laws and regulations. Park and Park [11] categorized defect cases of building equipment found in construction sites by type: design defect, defect arising out of other process, construction defect, defect arising out of management negligence, and suggested countermeasures to reduce the defects repeatedly found in construction projects.

Likewise, various studies have been conducted on building equipment, but there have been few studies conducted on a required knowledge system of building equipment for CMrs. Hence, the aim of this study is to suggest a plan for improving the capacity of CMrs by reviewing the required knowledge systems and understanding the knowledge levels of building equipment of CMrs.

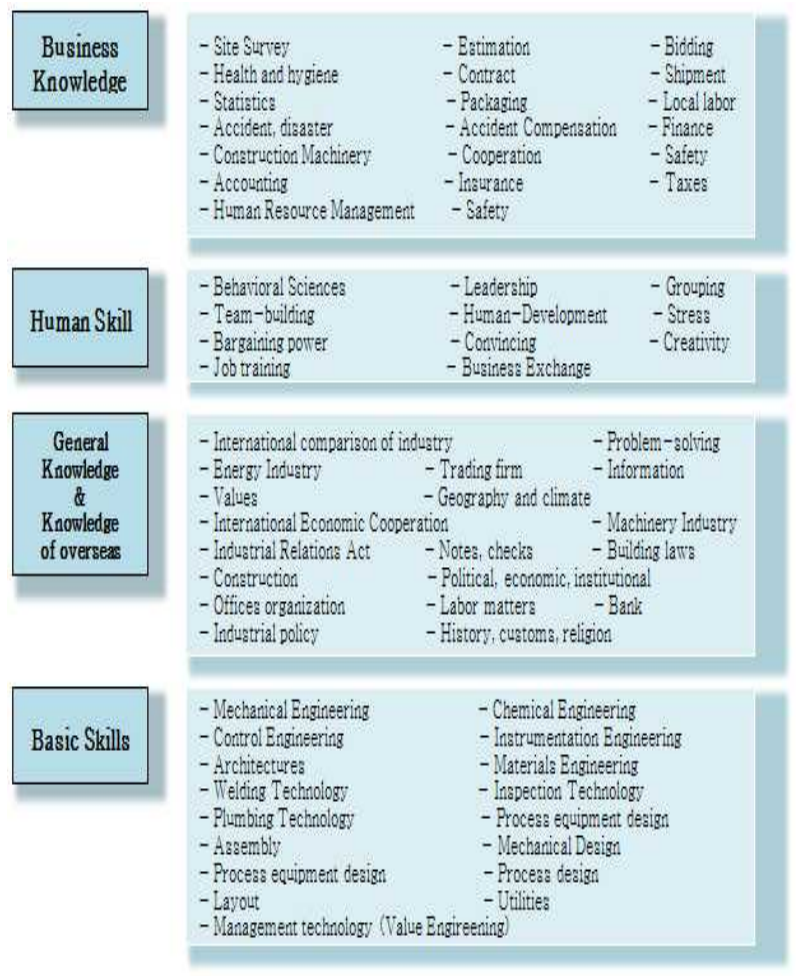

Figure 2. Knowledge required by Project Managers

\subsection{Knowledge system required for $\mathrm{CM}$ by phase and field}

The education program for CMrs developed by the Human Resource Development Council under the Japan Engineering Promotion Association, as indicated in Figure 2, consists of Business Knowledge, Human Skill, General Knowledge and Knowledge of Overseas Practices, and Basic Skill.

Basic Skill includes techniques of plumbing, assembly and welding. While systematic training programs are provided in Japan to foster eligible engineers, there are few engineer fostering programs currently provided in Korea.

\section{Knowledge of building equipment required of CMrs at the design phase}

\subsection{Overview of the survey}

The questions for the questionnaire on the knowledge required of CMrs at the design phase were selected through a preliminary survey and interview with equipment $\mathrm{CMrs}$ and construction CMrs. The preliminary survey was conducted on the CMrs involved in the equipment design and equipment field and the architects and CMrs involved in the architectural field. The survey was conducted for one month from September through October, 2010. 57 questionnaires were distributed to equipment CMrs, and 47 completed questionnaires or 81.2\% were collected. 61 questionnaires were distributed to construction CMrs, and 45 completed questionnaires or $73.7 \%$ were collected. Table 2 shows the general information of the respondents, such as gender, years of work experience and position.

The questionnaire was largely divided into the following categories: securing of the space for building equipment at floor plan, installation of building equipment, maintenance and utilization of 
building equipment, and detailed requirements for building equipment plan. The detailed questions were drawn through the preliminary survey and interview with equipment $\mathrm{CMrs}$ and construction CMrs, as shown in Figure 3.

Table 2. General information of the respondents

\begin{tabular}{|c|c|c|c|}
\hline \multicolumn{2}{|c|}{ Respondents } & \multirow{2}{*}{$\begin{array}{c}\text { Facility } \\
\text { designer and } \\
\text { project } \\
\text { manager } \\
\text { (person) } \\
47\end{array}$} & \multirow{2}{*}{$\begin{array}{c}\text { Architectural } \\
\text { designer and } \\
\text { project } \\
\text { manager } \\
\text { (person) }\end{array}$} \\
\hline & Male & & \\
\hline Gender & Female & 5 & 2 \\
\hline \multirow{3}{*}{$\begin{array}{c}\text { Years of } \\
\text { work } \\
\text { experience }\end{array}$} & $1 \sim 5$ years & 10 & 8 \\
\hline & $5 \sim 10$ years & 28 & 21 \\
\hline & $\begin{array}{c}\text { Over } \\
10 \text { years }\end{array}$ & 14 & 18 \\
\hline \multirow{4}{*}{ Position } & Employee & 7 & 5 \\
\hline & $\begin{array}{l}\text { Assistant } \\
\text { manager }\end{array}$ & 11 & 7 \\
\hline & Manager & 20 & 19 \\
\hline & $\begin{array}{c}\text { Head of } \\
\text { department }\end{array}$ & 14 & 16 \\
\hline \multicolumn{2}{|c|}{ Total } & 52 & 47 \\
\hline
\end{tabular}

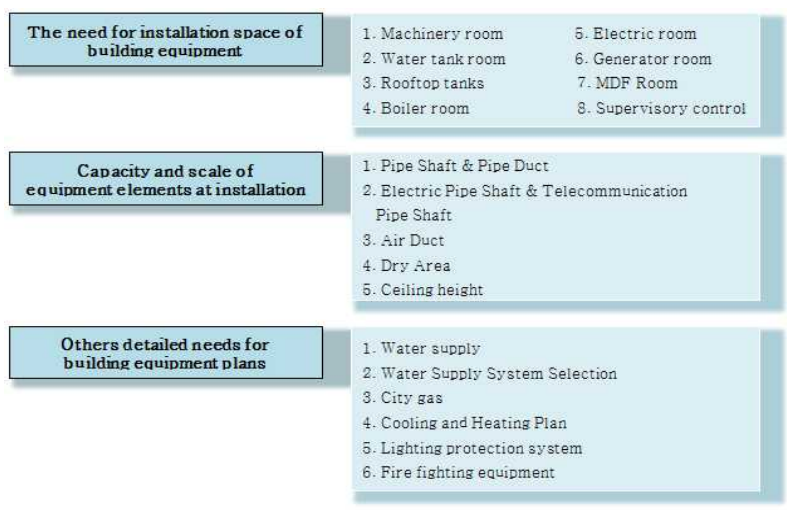

Figure 3. Details of questionnaire items

\subsection{Survey results}

To meet users' needs and wants, more functions are required of building equipment. The cost and space of equipment are also increasing in a corresponding manner. Therefore, the space for the building equipment should be considered at the design phase. The questions on the questionnaire covered the securing of the space for building equipment at the floor plan or design process, the installation and management of the building equipment, and other details including the need, location and capacity and scale by equipment.

\subsubsection{Securing of the space for building equipment at floor planning}

The knowledge level on the securing of the space for building equipment required of CMrs by equipment designers and CMrs in the equipment field was surveyed. Not only should the space to incorporate the building equipment required at the project planning and design phase be estimated, but the location of each room and the capacity and the scale of each piece of equipment should also be reflected according to the plumbing plan. Figure 4 shows the survey results.

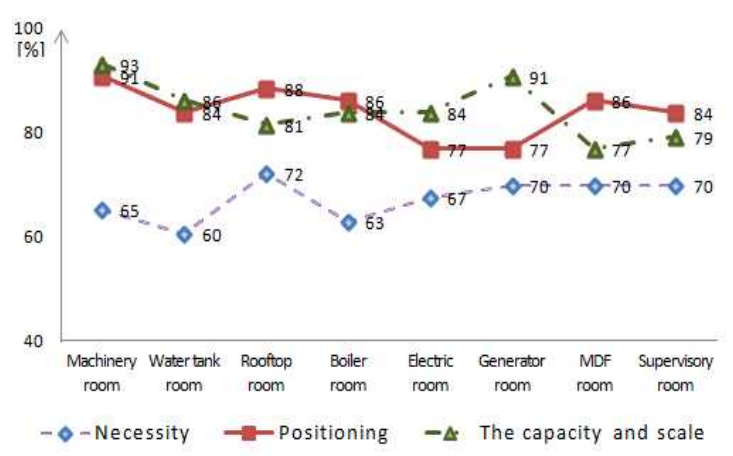

Figure 4. Knowledge level of architects and CMrs in architectural field expected by designers and CMrs in equipment field

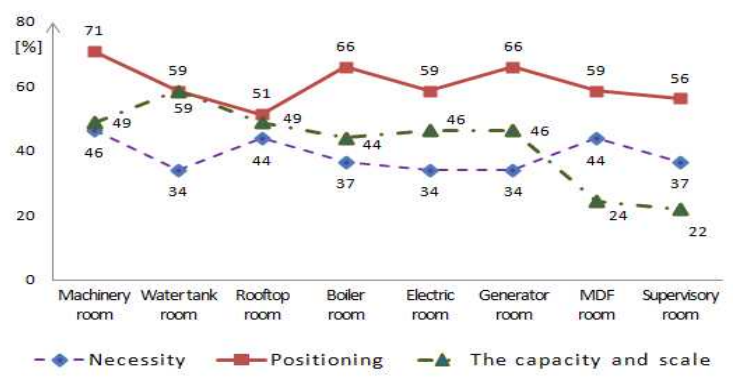

Figure 5. Actual knowledge level of architects and CMrs in architectural field 
The results of the survey on the current knowledge level of architects and CMrs in the architectural field on the securing of the space are shown in Figure 5. In all responses, the knowledge level did not meet the knowledge level expected by equipment designers and CMrs in the equipment field. The differences were bigger in the areas of the capacity and the scale of building equipment.

\subsubsection{Installation and management of building equipment}

According to functional requirements, the equipment may vary in size, and the following items should be thoroughly reviewed from the design phase due to their scale and interference. Pipe $\operatorname{shaft}(\mathrm{P} / \mathrm{S})$, pipe $\operatorname{duct}(\mathrm{P} / \mathrm{D})$, electric equipment pipe shaft(EPS), telecommunication pipe shaft(TPS), air $\operatorname{duct}(\mathrm{A} / \mathrm{D})$, dry air $\operatorname{duct}(\mathrm{D} / \mathrm{A})$, and the ceiling height and path required to install equipment were surveyed by categorizing them according to need, location, capacity and scale to reflect the results at the design phase.

Figure 6 shows the results of the survey of the knowledge level on the installation and management of building equipment of architects and CMrs in the construction field expected by equipment designers and CMrs in the equipment field. The comparison of the actual knowledge level of architects and CMrs in the architectural field and the knowledge level of architects and CMrs in the architectural field that was expected by the equipment designers and CMrs in the equipment field showed that with the exception of the item of ceiling height, the actual knowledge level of architects and CMrs in the architectural field did not meet the expectations of equipment designers and CMrs in the equipment field.

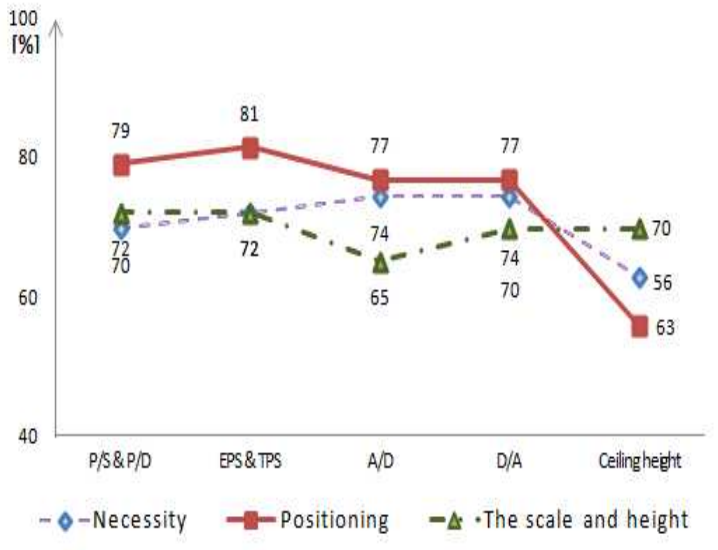

Figure 6. Knowledge level of architects and CMrs in architectural field expected by designers and CMrs in equipment field

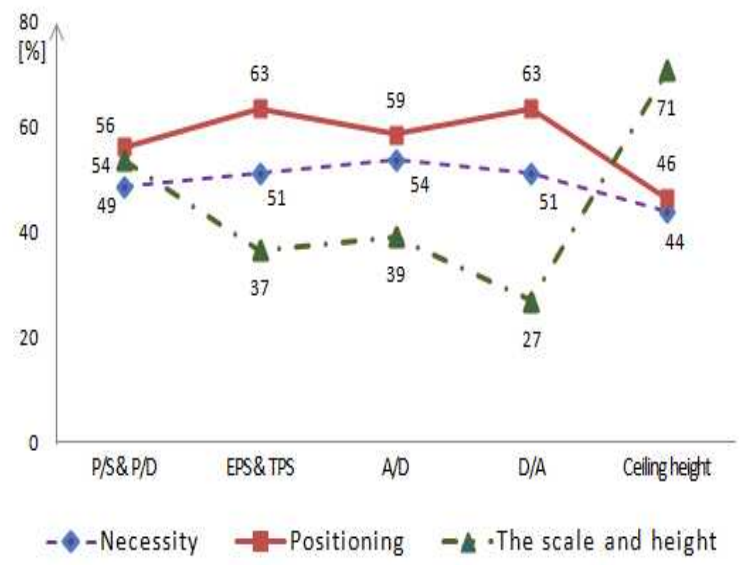

Figure 7. Actual knowledge level of architects and CMrs in architectural field

\subsubsection{Other requirements for a building equipment plan}

To produce a building structure that satisfies the demands of users, the basic requirements for the equipment were surveyed, including water supply and use of underground water, selection of the water supply method, use of city gas, cooling and heating plan, lightning protection system, and fire fighting equipment. The survey results are indicated in Figures 8 and 9. 


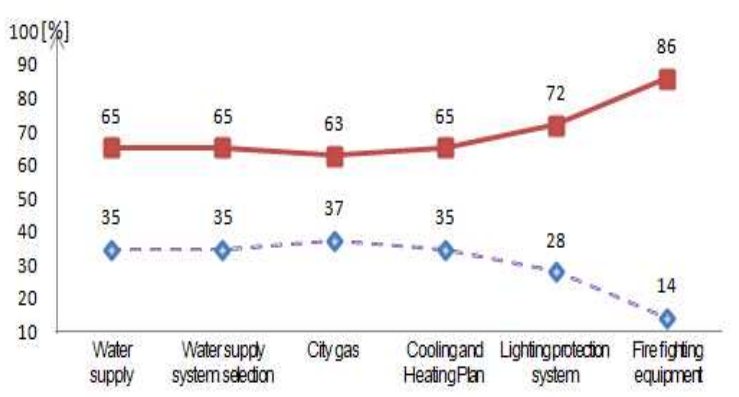

- $\bullet$ - Only checking requirements $\rightarrow-$ Check and propose alternative

Figure 8. Knowledge level of architects and CMrs in architectural field expected by designers and CMrs in equipment field

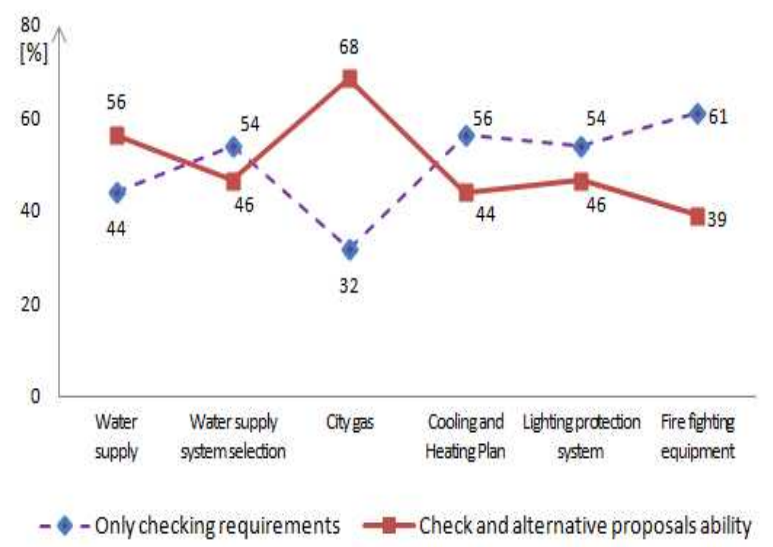

Figure 9. Actual knowledge level of architects and CMrs in architectural field

\section{Comparison of the expected knowledge level} of building equipment and the actual knowledge level

\subsection{Knowledge required for securing of the space at floor plan}

The knowledge of architects and CMrs in architectural field on the securing of the space for building equipment that was expected by equipment designers and CMrs in equipment field includes the capacity and scale of the equipment to be installed, which is used as the basis to determine the required space, and even includes higher-level knowledge such as the location and the spatial need for the equipment. But the actual knowledge level of architects and CMrs in architectural field does not meet the expected knowledge level.

As presented in Figure 10, in terms of the capacity and scale of equipment used as the standard to determine the required space for the equipment, there is a big difference between the actual knowledge level and the expected level. In addition, it was found that the knowledge level required to understand the space required for equipment and to determine the location of the equipment did not meet the expected levels.

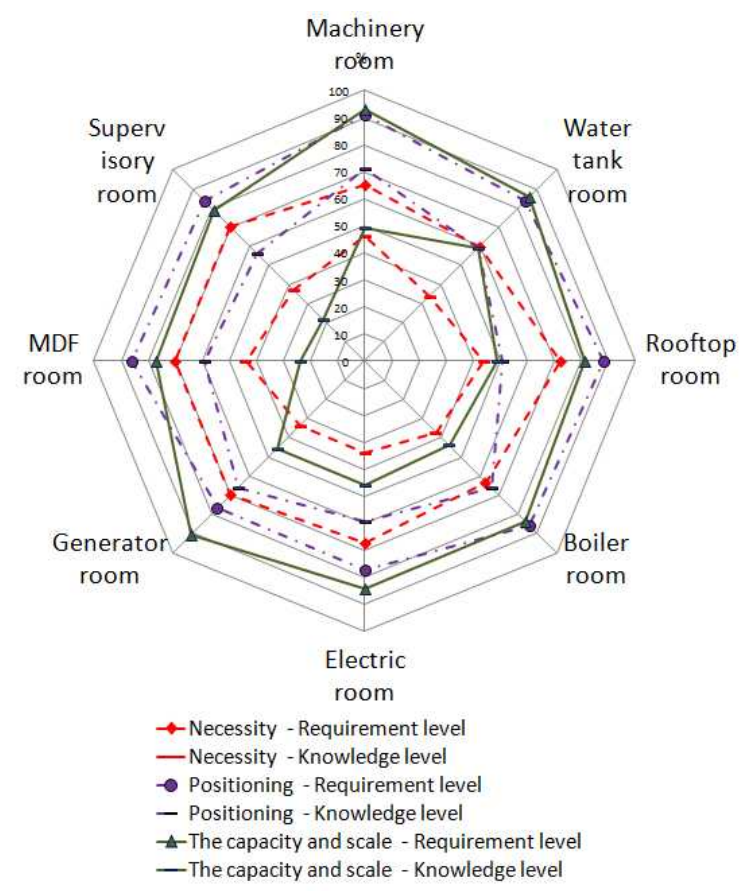

Figure 10. Space required to install building equipment

\subsection{Knowledge required for the installation and management of building equipment}

In terms of equipment elements such as $\mathrm{P} / \mathrm{S}$, EPS and A/D, the actual knowledge level of architects and CMrs in the architectural field was shown to be lower overall than the expected level, as shown in Figure 11. 


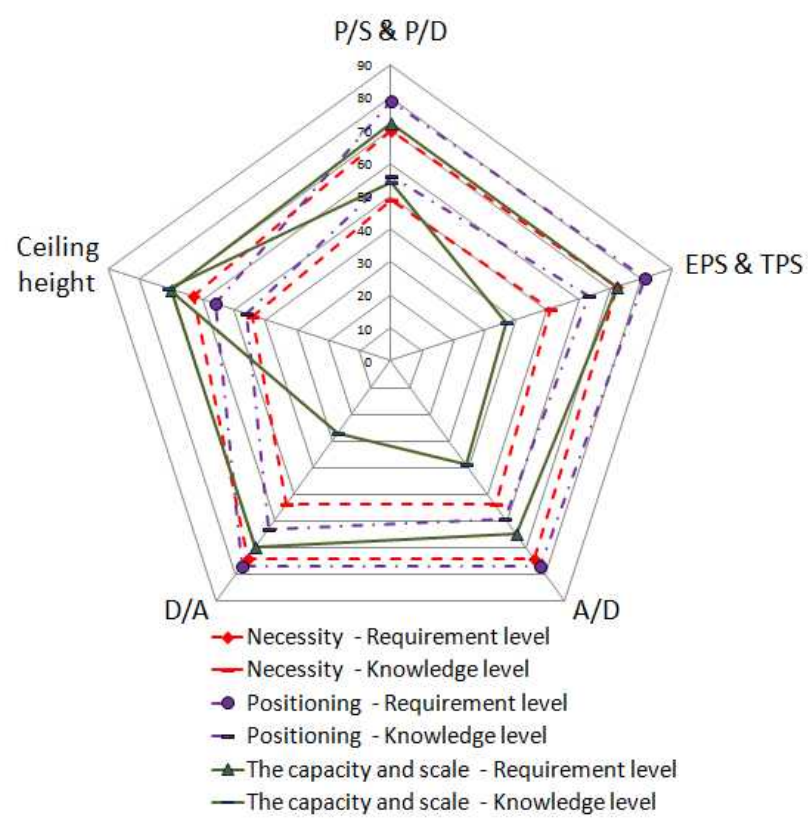

Figure 11. Capacity and scale of equipment elements at installation

\subsection{Other knowledge required for building equipment plan}

In the comparison of other details for building equipment plan, the equipment designers and CMrs in equipment field expected architects and CMrs in the architectural field to have a level of knowledge that would enable them to go beyond just checking the equipment and provide an alternative, but the architects and CMrs in the architectural field do not currently meet the knowledge level.

In particular, in terms of lightning protection system and fire fighting equipment, the actual knowledge level of architects and CMrs in the architectural field fell greatly short of the expected level. It is believed that since the lightning protection system and the fire fighting equipment are perceived as professional fields, architects and CMrs in the architectural field rely on professionals in those fields.

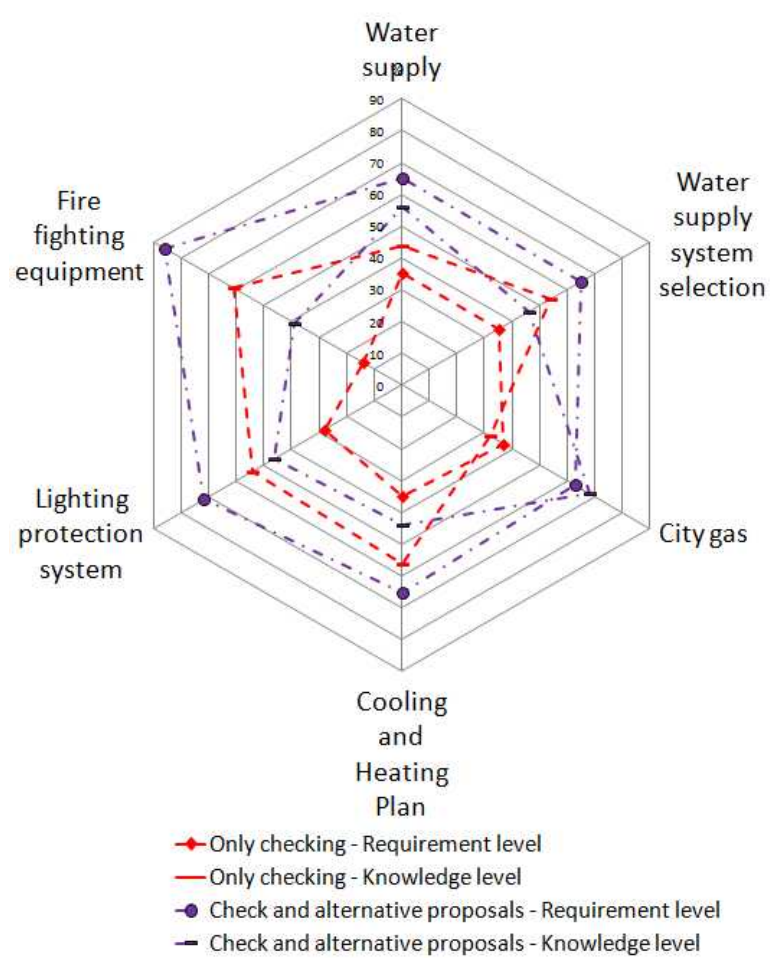

Figure 12. Other details required for building equipment plan(\%)

\section{Conclusion}

As more buildings are required to have more functions, building equipment plays a greater role in building structure. Currently, there is a lack of CMrs who have knowledge on building equipment. Most of the CMrs in charge of construction projects majored in construction engineering. To be effective managers, CMrs should be equipped with knowledge on building equipment.

Despite this fact, it is too difficult for CMrs majoring in construction engineering to have sufficient knowledge on building equipment. But as the demand for building equipment has been gradually increasing, CMrs should strive to gain the knowledge on building equipment expected by equipment designers and CMrs in the equipment field, to carry out their construction projects in an effective and efficient manner. 


\section{References}

1. Park JI, Kim SH. A study on the laws of building service system construction. International Journal of Air-Conditioning and Refrigeration. 2003 Jan;15(1):67-72.

2. Kim HB. The planning to building facility considering maintenance. Proceedings of the Korean Institute of Illuminating and Electrical Installation Engineers. 2003 Aug;17(4):63-77.

3. Park JI, Kim SH. A study on the laws of mechanical system construction. In: Kang SH editor. Proceedings of the Society of Air-Conditioning and Refrigeration Engineers of Korea 2002 Summer Conference; 2002 jun 27-29; Yong Pyong Resort. Seoul (Korea): the Society of Air-Conditioning and Refrigeration Engineers of Korea; 2002. p. 1100-5.

4. $\mathrm{Yu} \mathrm{JH}$, Choi $\mathrm{JH}$. Analysis of relative importance of critical success factors in the various types of CM project. Journal of the Korean Society of Civil Engineers. 2004 Mar;24(2): 255-63.

5. Ryou WS, Pyun HJ, Kim KR, Lee YS, Kim JJ. Improvements for CM service and practice through analyzing domestic CM cases. Journal of Architectural Institute of Korea. 2003 Jan; 19(1):153-60

6. Lee JE, Kim HS. Needs and opportunities analysis of CM services during pre-construction stages. Journal of Architectural Institute of Korea. 2003 Apr;19(4):153-60.

7. Yoon TK, Chung JY. The method improving the productivity of a project through construction management techniques. In: Oh SG editor. Proceeding of the Korea Institute of Building Construction; 2005 May 21; Seoul National University of Science \& Technology. Seoul (Korea): the Korea Institute of Building Construction; 2005. p. 133-6

8. Kim SC, Yoon JS. Analyzing korean construction management market and perception. Journal of Architectural Institute of Korea. 2010 Mar;26(3):85-92.

9. Chung KS. Engineering technology for designing green building, International Journal of Air-Conditioning and Refrigeration. 1998 Aug;27(4):347-57.

10. Cho DW. Green building and facility, Proceedings of the Society of Air-Conditioning and Refrigeration Engineers of Korea 1999 Energy conservation seminars; 1999 Oct; Seoul (Korea). Seoul (Korea): the Society of Air-Conditioning and Refrigeration Engineers of Korea; 1999. p. 65-81

11. Park JK, Park JI. Analysis of building service system construction flow, In: Choi YD editor. Proceedings of the
Society of Air-Conditioning and Refrigeration Engineers of Korea 2006 Summer Conference; 2006 jun 21-23; Pyong Chang Phoenix Park. Seoul (Korea): the Society of Air-Conditioning and Refrigeration Engineers of Korea; 2006. p. 548-53. 